\title{
Trabalho decente e precarização*
}

Cinara L. Rosenfield

Introdução

O presente estudo analisa o significado das novas carreiras e percursos profissionais emblemáticos da Sociedade da Informação (cf. Castells, 1999), especialmente os novos contornos assumidos pela organização do trabalho por projetos e gestão de objetivos.

$\mathrm{Na}$ atual fase do capitalismo dominam as empresas divididas em unidades autônomas, organizadas por "projetos", com forte redução dos níveis hierárquicos. Para os trabalhadores em todos os níveis, a valorização recai sobre a capacidade constante de adaptação, de flexibilidade e de gestão de suas empregabilidades via o engajamento em projetos sempre transitórios. Boltanski e Chiapello (1999) denominam esse modelo de cité par projets ${ }^{1}$, um novo regime de justificação no qual o destaque é criar e se inserir em redes, ser móvel e polivalente. As pessoas valorizadas são aquelas que se engajam pessoalmente em novos projetos, demonstram grande flexibilidade, dispõem de boas competências relacionais para se integrar em redes e agem de maneira autônoma mostrando-se dignas de confiança. $\mathrm{O}$ trabalhador passa a ser seu próprio empreendedor, ao dispor de suas próprias competências e seus recursos emocionais a serviço de projetos individualizados.

Os quadros superiores das grandes empresas de Tecnologias de Informação $(\mathrm{TI})^{2}$, nosso objeto empírico de investigação, são exemplares desse
* Contribuiu de maneira decisiva para este trabalho a bolsista de iniciação científica Thays Wolfarth Mossi (Pibic-CNPq).

1. A noção de cité foi proposta originalmente por Boltanski e Thévenot (1991) como um modelo de justiça ou universo de justificação legítima. Os autores identificam, nesta obra, seis modelos de cités: as cidades inspirada, doméstica, do renome, cívica, mercantil e, por fim, industrial. Boltanski e Chiapello (1999) acrescentarāo ainda a cidade por projetos, que inaugura um novo universo de justificação.

2. Utilizamos TI e não TIC (Tecnologias de Informação e Comunicação) pelo fato de nosso objeto empírico ser os quadros superiores que trabalham com tecnologias informacionais, mesmo quando inseridos em empresas de comunicação. Além disso, atualmente as tecnologias informacionais englobam igualmente os serviços de comunicação como Internet e telefonia móvel, o que 
justificaria de antemão a substituição do termo. processo ao construírem a imagem do fim da carreira clássica de progressão sempre ascendente em uma mesma empresa em prol de um percurso ou trajetória profissional marcado pela mobilidade, pelo nomadismo intra e interfirmas, de acordo com sua inserção em diferentes projetos. Indagandonos sobre essa nova configuração do trabalho, nosso objetivo é refletir se a mobilidade dos quadros superiores significaria uma nova relação com o trabalho marcada pela flexibilidade positiva ou uma gestão da justificação de um contexto de fragilização e precariedade.

Os quadros superiores de grandes empresas, chamados cadres pelos franceses e managers pelos anglo-saxões, seguindo a noção de um "novo espírito do capitalismo" (cf. Idem), seriam a personificação da polivalência, da adaptabilidade e do risco; seriam os "Grandes", os nômades, os críticos e autônomos, se comparados aos "Pequenos", incapazes de mudar de projeto, tão arraigados à ideia de segurança do emprego. No lugar do cadre que possui emprego estável em uma grande empresa, surge o colaborador intermitente remunerado de diferentes maneiras. Ele teria uma missão de expert, de chefe de projeto e ainda de gestor de seu próprio percurso, detentor de competências transferíveis em um mercado de trabalho mundial (cf. Bouffartigue e Pochic, 2001). Nem todos os quadros superiores encaixam-se nesse perfil, estando aqueles do setor industrial e detentores de saberes específicos mais fragilizados do que aqueles do setor financeiro e tecnológico, e os consultores das mais variadas áreas. Daí nosso interesse nos profissionais ligados às empresas do setor de TI, marcadas por políticas de management centradas no trabalho por projetos e gestão de objetivos, onde a mobilidade positiva pode ser confrontada a um contexto social de fragilização da relação com o trabalho.

Os quadros superiores são colaboradores com formação profissional de nível superior, exercendo funções que demandam operações intelectuais de julgamento e iniciativa, e que comportam um alto nível de responsabilidade. Possuem uma imagem de trabalhadores excepcionais que, considerados como "de confiança" (cf. Bouffartigue, 2001), expandiram suas características ao conjunto dos trabalhadores (implicação subjetiva, responsabilidade, autonomia) e, no entanto, passaram a vivenciar também características típicas dos trabalhadores "clássicos" ou menos qualificados (aumento da carga de trabalho, níveis elevados de exigência, insegurança).

Nosso objetivo é conhecer os paradoxos presentes na vivência concreta desses quadros superiores de empresas de TI, os "trabalhadores do conhecimento", com base em 22 entrevistas semidiretivas. Trata-se de quadros médio-superiores (gerentes, consultores e diretores) e quadros superiores 
(executivos, sócios ${ }^{3}$ ), trabalhando sob contrato de trabalho assalariado ou como autônomos ${ }^{4}$, conforme Diagrama a seguir de um projeto típico de uma equipe de desenvolvimento de software.

Diagrama

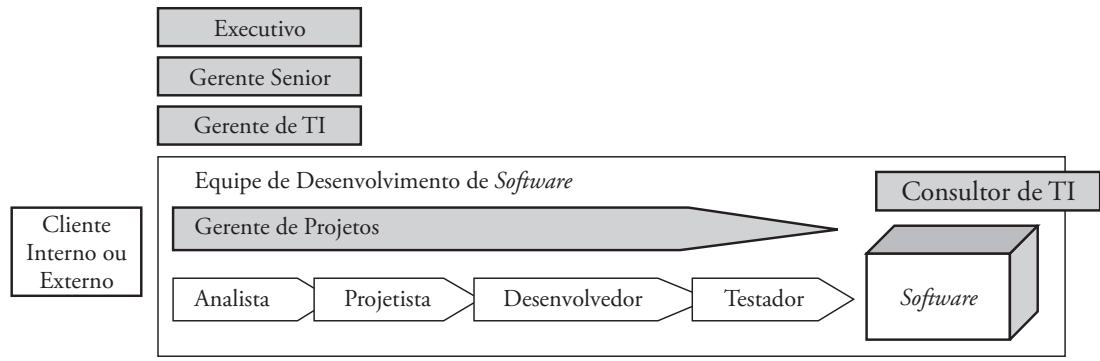

Esses atores personificam a figura dos "Grandes", dos ganhadores da nova ordem social, dos experts móveis, facilmente empregáveis, para quem a estabilidade no emprego significaria, a priorie ao contrário do trabalhador clássico, fragilização, ausência de riscos e, portanto, de progressão profissional. Estamos diante de uma flexibilidade qualificante ou de um modelo inexorável que deve necessariamente ser seguido sob pena de fragilização?

Nossa hipótese é de que, nas organizações estruturadas por projetos, a consecução de objetivos e sua superação são medidas do valor de si no trabalho. Como a gestão de si mesmo e o sucesso pessoal são condições de permanência e ascensão, não há segurança de êxito senão sob a forma de fortalecimento do "eu" e na crença moral do reconhecimento do valor de seu trabalho. O risco e a aventura aparecem como um novo "bem viver", sem poder coercitivo e livre das amarras da heteronomia típica da organização do trabalho. O trabalho autônomo e ousado reabilitaria a noção de trabalho como "obra", uma vez que de responsabilidade única dos atores. Não obstante, trata-se de uma justificação moral, uma vez que "a própria legitimidade como vencedor baseia-se na adesão a essa premissa" (Luci, 2007).

O paradoxo desvela-se em um discurso de sucesso do "eu" que remete a um sujeito autônomo e senhor de seu destino, sem amarras ou coerçōes de natureza social (segundo a imagem de que o ator pode gerir sua vida profissional livremente). Nosso argumento é de que o "empreendedorismo de si mesmo" configura-se como justificação e gestão da precarização, aqui entendida como processo de institucionalização da instabilidade.
3. Neste trabalho serão chamados, em seu conjunto, de quadros superiores. Os sócios das empresas de TI não constituem, por excelência, nosso objeto empírico de investigação, no entanto eles integram minoritariamente as entrevistas como informantes privilegiados deste mercado de trabalho, a despeito de não estar em questão suas próprias trajetórias - a não ser quando se articulam com uma trajetória anterior de assalariamento ou consultoria.

4. Inicialmente, a condição de assalariamento parecia ser incontornável para refletir acerca da nova configuração de mobilidade e flexibilidade. No entanto, com o desenvolvimento das entrevistas como veremos mais detidamente adiante - foi possível constatar que a relação do trabalhador com o trabalho e com a empresa independentemente do fato de haver um contrato CLT ou uma prestação de serviço exclusiva como Pessoa Jurídica (PJ). Esta diversidade de vínculo constitui mais uma forma de flexibilidade do contrato formal de trabalho. 
Nesse sentido, o trabalho permanece como categoria de análise crucial na compreensão dos critérios morais que fundamentam as relações sociais na sociedade capitalista moderna. A partir da constatação de que "possivelmente a distância entre as expectativas do mundo socialmente vivido e as temáticas da reflexão socioteórica nunca tenha sido tão grande quanto hoje" (Honneth, 2008, p. 47) - ou seja, na academia o trabalho perde força como categoria de análise, enquanto na sociedade vivida continua sendo fonte de angústia e incerteza para aqueles que dele dependem -, Honneth busca redefinir o lugar da categoria trabalho no marco da teoria social, a fim de desvelar uma perspectiva de melhoria qualitativa do trabalho que não seja utópica. Para tal, discute o aporte do trabalho como contribuição ao bem geral: o trabalho seria lócus da integração do indivíduo ao todo social e não somente meio de suprir necessidades, articulando a abordagem do trabalho entendida como integração sistêmica (produtividade) com a do trabalho como forma de integração social (dependente de princípios morais). Seguindo Hegel e Durkheim, Honneth desenvolve o argumento de que o trabalho tem valor imanente (e, portanto, independeria das formas que assume na sociedade supostamente do "fim do trabalho") no que se refere às formas de reconhecimento social, uma vez que integra um conjunto de normas morais tidas como válidas e legítimas.

Uma dissolução da contradição aqui esboçada só pode acontecer quando as normas (a saber, morais) referidas sejam compreendidas como base contrafatual da organização capitalista do trabalho. Pelo fato de que todos os participantes só têm a chance de compreender o sentido desta nova forma econômica e de considerá-la como propícia para o "bem geral" se pressupuserem mentalmente as duas normas expostas por Hegel - a saber, primeiro, que ela dote o trabalho feito profissionalmente com um salário mínimo e, segundo, que dê às atividades desempenhadas uma forma que permita reconhecê-las como contribuição para o bem geral -, a organização capitalista do trabalho mediada pelo mercado repousará sobre condiçôes normativas que não perdem sua validade mesmo quando fatualmente sua vigência é suspensa. Falar aqui de uma "vinculação", portanto, significa tornar o funcionamento do mercado capitalista de trabalho dependente de condições que ele próprio não necessariamente precisa poder cumprir: os acontecimentos no mercado de troca do trabalho, amplamente intransparente, realizam-se sob pressupostos de normas morais que permanecem válidas mesmo quando o desenvolvimento histórico as transgride. Ao mesmo tempo, estas certezas normativas de fundo formam o recurso moral ao qual os atores podem recorrer quando quiserem questionar as regulamentações 
existentes na organização capitalista do trabalho: não há necessidade então de recorrer a um reino de valores transcendentes ou a princípios universalistas, mas somente à mobilização daquelas normas que já estão admitidas como condição da compreensão e da aceitação na constituição do moderno mercado de trabalho (cf. Idem, p. 59).

Assim, o trabalho dos quadros superiores de TI desponta como objeto privilegiado para explorar o sentido imanente do trabalho na atual fase do capitalismo. Parafraseando Honneth (Idem, p. 59), suas "certezas normativas de fundo formam o recurso moral ao qual os atores recorrem" para compreender as "regulamentações existentes na organização capitalista do trabalho". É possível, pois, concluir acerca de uma adesão/aceitação intrínseca destas normas mesmo quando não se mostram empírica e concretamente efetivas.

\section{0 trabalho dos quadros superiores}

Os quadros superiores são um híbrido de capital e trabalho (cf. Santos, 2007), isto é, são trabalhadores, ou assalariados, uma vez que estão submetidos a um contrato de trabalho (CLT) ou um contrato exclusivo de prestação de serviço como formalmente autônomo (PJ), e ao mesmo tempo representam as diretivas do capital. A novidade é que o "novo espírito do capitalismo", marcado pela valoração da construção de redes, e sobretudo pela valorização da polivalência, da flexibilidade, da mobilidade e da adaptabilidade, transforma essa categoria social em representante de si mesma.

Lopez-Ruiz (2007) analisa os executivos das corporações transnacionais a partir de duas categorias típicas ideais: "trabalhadores de altas rendas" e "capitalistas em relação de dependência". São trabalhadores (vendem seu tempo em troca de um salário), mas não tradicionais, dados seus níveis de instrução e a alta renda que recebem por seu trabalho. Esta renda seria um dos critérios de definição, no entanto ela não é capaz de isoladamente contribuir na formação e na consolidação de um ethos da corporação (grandes empresas). Tanto é que dificilmente executivos se autoqualificam como trabalhadores, sendo identificados com homens e mulheres de negócios ou colaboradores. Embora muitas vezes recebam salários variáveis, que dependem do lucro das empresas, não é possível afirmar que seus objetivos estejam sempre e invariavelmente atrelados àqueles dos dirigentes ou acionistas, de maneira a poder qualificá-los como capitalistas. Segundo Lopez-Ruiz, os executivos (ou quadros superiores, para nós) são proprietários de um "capital-destreza" que não é "capital-dinheiro". Seu capital-destreza é com- 
posto por competências de gerenciamento aliadas à capacidade de agregar valor à empresa. "Esse capital inclui atitudes essenciais como a flexibilidade e o desapego de esquemas tradicionais - e também de lugares, pessoas e coisas -, e a capacidade, sagacidade e astúcia para a tomada de decisões que impliquem risco" (Idem, p. 50).

Todavia, o mercado onde se investe o capital-destreza é o mercado de trabalho. Isso explicaria a rotatividade interfirmas, pois é preciso decidir onde e quando aplicar ou retirar seu capital-destreza:

No entanto, apesar da liberdade de movimento de capitais que, segundo parece, há no mercado do capital-destreza, decidimos chamar o seu possuidor "capitalista em relação de dependência”. [...] Como seu capital é constituído por destrezas e habilidades de gestão capitalista, para produzir valor, precisa ser investido (como qualquer tipo de capital) (Idem, p. 51).

Assim, se, de um lado, o primeiro compromisso deste profissional é consigo mesmo e com sua carreira, de outro, ele é dependente das empresas que o contratam. Enquanto os demais trabalhadores são levados a estreitar sua relação e seu compromisso com a empresa, esse outro tipo de trabalhador de alta renda relaciona-se, antes de tudo, com seu próprio percurso profissional. É a figura do trabalhador empreendedor, do empresário de si mesmo, do responsável do seu próprio capital-destreza, que deve gerir sua carreira e a própria vida segundo as regras do capital. Mas esta gestão do percurso profissional traz consigo o paradoxo da liberdade atrelada ao assalariamento, ou ao vínculo autônomo que o mascara - como no caso dos trabalhadores sob o formato PJ -, proposto pelas empresas contratantes.

$\mathrm{O}$ discurso managerial difunde e incita a autogestão das carreiras profissionais dos quadros superiores nos moldes dos profissionais liberais - daí decorre não haver nenhuma contradição em vincular-se a empresa como um trabalhador formalmente autônomo (PJ). O desejável é a mobilidade, o risco, o fim da noção de carreira em prol da ideia de empregabilidade, o que remete à autonomia, à autenticidade, à realização de si no trabalho. A noção de chefe de projeto se traduz em um significado móvel, transitório, sem amarras, de temporalidade. Os projetos da empresa devem combinarse a um projeto de desenvolvimento pessoal. No entanto, é possível vislumbrar um aparente paradoxo no objetivo da mobilidade. A empresa, a despeito de cultuar o risco e a autonomia de seus quadros, buscaria fidelizar, sobretudo mediante altos salários, essa população de trabalha- 
dores nômades com alto valor de expertise e de conhecimento agregado, notadamente as profissōes ligadas às inovaçóes tecnológicas.

Bouffartigue e Pochic (2001) afirmam que tal nomadismo voluntário é um mito, pois reverte, de maneira frequente, na passagem do trabalhador para a condição de autônomo ou independente, no desemprego, em formas atípicas de emprego, formas essas a que só se resignam os trabalhadores mais fragilizados no contexto do mercado de trabalho. O paradoxo é que se, de um lado, esses elementos levam à relativização da noção de trabalhador nômade, de outro, indicadores de natureza subjetiva atestam de fato uma atitude positiva por parte dos trabalhadores que integram os quadros superiores diante da mobilidade e de seus potenciais de empregabilidade. É possível identificar em populações de jovens quadros superiores de empresas de TI uma ambição sempre renovável, um desejo de instabilidade e mutabilidade em busca de um percurso ascendente. Os autores sustentam que só os cadres mais fragilizados são levados a renunciar à norma do emprego assalariado estável. Nesse sentido, o mito serviria a ocultar uma realidade de dificuldades e temores.

A autogestão de carreira, de fato, significa uma passagem para a noção de percurso que remete ao conceito de competência (cf. Rosenfield e Nardi, 2006). Dispor de competências permite ao trabalhador ultrapassar os limites da empresa e se lançar num mercado de trabalho bem mais amplo. Se a carreira era concebida como uma progressão em um espaço predeterminado (a empresa), o percurso - noção sem passado institucional - evoca um caminho profissional livre de elos e comprometimentos, possibilitando um distanciamento entre os destinos da empresa e os dos assalariados (cf. Monchatre, 2007). A instabilidade do emprego combina de maneira satisfatória com a noção de uma sociedade de risco. Se esta pode ser a realidade tanto para trabalhadores assalariados subalternos como para os quadros superiores, afirma-se, no entanto, que para aqueles significa fragilização e precariedade, enquanto para estes trata-se de fortalecimento e autonomia na gestão da própria vida profissional em meio a uma infinidade de alternativas. A autora argumenta que a "desinstitucionalização" da carreira está atrelada à institucionalização progressiva de uma "securização" do percurso, por meio das competências que portam esses trabalhadores. A mobilização da noção de competência insere-se em uma "retórica de desestabilização do emprego que legitima a delegação aos indivíduos da gestão de seu futuro, e a ideia de empregabilidade torna-se a principal contrapartida à mobilização no trabalho". E conclui: "Mas na falta de novas regulações sobre a valorização do trabalho ao longo da vida, a lógica 
5. Traduçôes livres de todos os textos em língua estrangeira. de percurso arrisca fazer do mercado o grande (des)ordenador dos destinos individuais" (Idem, p. 528)

\section{A institucionalização da instabilidade}

A mobilidade desses quadros dá-se no interior da própria empresa ou entre as poucas empresas do mesmo porte, de maneira a manter posições e status já adquiridos. Tal mobilidade é de responsabilidade do próprio indivíduo. Raramente ele é alçado pela própria hierarquia a uma posição superior. As carreiras devem ser planejadas e geridas pelo próprio empregado, indicando um paradigma de "empreendedorismo do empregado": seja para progredir dentro da empresa, seja para montar o próprio negócio ou, ainda, aventurar-se em algum negócio inovador.

Mas eu quero aumentar minha área de ação, não ficar só lá no mesmo lugar. Depende de mim, né? Nas empresas desse tamanho depende da pessoa arrumar o seu espaço. É incentivado um certo nível de empreendedorismo. A política hoje dentro da empresa é assim: você é responsável por sua evolução. Não é o gerente que diz: faça o treinamento na área. [...] Essa empresa quer pessoas que tenham iniciativa, pessoas que buscam crescer, são pessoas que interessam pra empresa, porque isso traz benefícios pra empresa (Homem, 52 anos, 33 anos em TI, CLT).

A mobilidade no interior das empresas assume contornos inéditos: os desafios são constantes, cada nova etapa (desejável e obrigatória) é como se fosse um novo emprego, o número de variáveis a controlar no dia a dia do trabalho não para de crescer, o engajamento a se adaptar e a se superar deve ser infinito, a concorrência pelos postos de trabalho de maior responsabilidade, reconhecimento, autonomia e remuneração impõe a individualização e o isolamento dos quadros superiores de TI.

Eu acho que deve dar na soma uns 28 anos de janela, né? Se chama de janela, desde lá no início, como estagiário, e só duas empresas [trabalhou só em duas empresas]. Mas a coisa mudou tanto ao longo dos anos dentro de cada uma. [...] Que é como se eu tivesse ficado, olha, no mínimo, umas seis empresas. Porque essa história dos desafios que eu fui colocado [...] eram desafios novos, que eu comprei eles todos, sem muito problema. Porque eu olhava e dizia assim: eu acho que eu faço. [...] Então, várias dessas oportunidades me mudaram pra uma "nova empresa”, que não tinha nada que ver. Tipo assim, o teu foco agora é esse, tu pega todas as pastas que 
tu guardou lá de e-mail daqueles assuntos, joga num canto lá e começa uma nova vida, entende? Porque as coisas não se confundiam de forma alguma (Homem, 50 anos, 14 anos em TI, PJ).

A mobilidade é enaltecida como característica desejável em qualquer carreira, mas apenas no limite de seu significado de enriquecimento de experiências. É preciso acumular competências e vivências que confiram um alto grau de empregabilidade ao trabalhador, ou seja, a bagagem profissional acumulada deve ser flexível e adaptável a novos empregos. Trata-se de tornarse moeda valorizada no mercado de trabalho. No entanto, é preciso saber igualmente estabilizar-se de maneira a mostrar-se fiel e seguro.

A mobilidade (hoje em dia) é fundamental pra que a pessoa alargue seu leque de conhecimento. E o pessoal mais novo não tem muita paciência, se as coisas não tão indo do jeito que querem, sempre tão surgindo oportunidades. E de repente não tá gostando de uma empresa, vai. Mas quando começa a subir pra níveis de liderança, começa a ficar mais estável. As próprias empresas hoje valorizam muito, assim, pessoas que tiveram mais de uma experiência. Mas também não quer dizer que o cara que troca de emprego a cada ano é bem visto. [...] Nós temos um sistema de avaliação que pontua, e as pessoas que são consideradas pessoas-chaves, a empresa faz tudo pra manter, porque essas pessoas vão trazer valor pra empresa (Homem, 52 anos, 33 anos de TI, CLT).

Pode-se afirmar que encontrar equilíbrio entre mobilidade como alargamento do leque de experiências e estabilidade como projeção para o futuro é uma tarefa paradoxal, sobretudo porque a adaptabilidade e a disposição à mobilidade não duram para sempre.

Então, na realidade, assim, enquanto eu vou pegando esses desafios novos, às vezes eu não me flagro, mas o tempo tá passando, e isso pra mim é bom, essa quilometragem. Considerando o mercado de TI, a gente sabe que a gente vive muito de projeto, projeto tem início, meio e fim, termina. Então, as coisas acontecem muito dinamicamente. E nesse dinamicamente, tu pode sair de uma empresa e ir pra outra, trocar de projeto dentro da mesma empresa. Agora, por outro lado, eu tô buscando essa estabilidade pra ter uma coisa mais consolidada no meu currículo. Não quero ser aquele currículo que trabalhou 25 anos numa empresa, mas também não quero ser aquele cara que na média fica um ano em cada empresa. Geralmente, ele é um pouco malvisto. E eu, eu acho que... tu tem que acreditar no teu potencial 
e entender que tu agrega valor. Tem que ser bom naquilo que tu faz, e saber no que que tu é bom. Mas... eh... dá um pouco de solidão, assim. A questão do gerente é um pouco solitária, assim (Homem, 34 anos, 13 anos de TI, CLT).

A noção de "ter" empregabilidade, ou seja, dispor da possibilidade el ou capacidade de empregar-se, assume novas proporções entre os quadros superiores de TI. A relação com a empresa se dá pela empregabilidade do trabalhador e não pelo seu vínculo empregatício. Assim, ter um vínculo empregatício de tipo CLT ou constituir-se como autônomo e prestar serviços como Pessoa Jurídica (PJ) para uma única empresa torna-se, para eles, uma questão secundária, pois não importa o vínculo, o que importa é fazer-se necessário para aquela empresa e garantir sua empregabilidade. Esse trabalhador toma para si a responsabilidade de seu valor no trabalho e sua importância é apanágio unicamente seu.

Porque a qualquer momento, mesmo que eu fosse empregado CLT, a [empresa] poderia chegar pra mim e dizer: eu não preciso mais de ti. Ou você não tá dando resultado... ou porque o mercado encolheu. Então o fato de ser CLT implicaria a mesma condição de causa e efeito. Ou seja, como empregador a minha decisão seria essa aí: a pessoa faz o trabalho? Ela é necessária? Sim ou não? E com base nisso é que eu decidiria se a pessoa fica ou não fica. E não pela questão de relação trabalhista, contratual. Então eu acho que eu teria o mesmo risco que sendo CLT, né? O fato de ser CLT teria, sei lá, uma multa de $40 \%$ do fundo de garantia. Bom, mas eu entendo que com uma relação de Pessoa Jurídica, na verdade eu tô recebendo adiantado esse valor. Eu faço a minha reserva. Então, caso a empresa não precise mais de mim, eu tenho a minha reserva. E o mercado que tá aqui à disposição, né? Sendo CLT ou PJ, se a empresa não precisasse mais de mim, ela ia me demitir. Eu não percebo qualquer relação, de percepção de curto, de médio e de longo prazo de descartabilidade (Homem, 36 anos, 15 anos em TI, PJ).

E ainda:

$\mathrm{Na}$ [empresa $\mathrm{Y}$ ] teve um período que eu fiquei como PJ, que eles mudaram o regime. E aí eu saí e continuei como PJ na [empresa Z]. E aí eles fizeram uma proposta pra mim como funcionário, que na época não era interessante, que eles não queriam mais trabalhar com terceiros. E aí eu tive que tomar a decisão também de ficar ou sair. E aí eu falei: "Não, pra mim não é interessante ficar, financeiramente nessas condiçōes como empresa eu ganho bem melhor". Então, por mais que CLT tenha 
os benefícios e tudo. Então, eu decidi: "Não, então eu não vou continuar, vamos rescindir o contrato". E aí eu fui trabalhar na [empresa W] como PJ (Homem, 34 anos, 13 anos de TI, CLT).

Se, de um lado, o ritmo, a tensão e o desafio conferem ao trabalho fortes emoções, de outro, os níveis de estresse são elevados. Dada a impossibilidade de uma rotina de trabalho e de controle de todos os elementos que compõem o trabalho, há uma tensão relevante entre as exigências a cumprir e os meios disponíveis para fazê-lo. Pessoalmente, o trabalhador que integra os quadros superiores das empresas de TI se coloca constantemente em perigo, obrigando-se a questionar seus limites e condições a cada novo desafio. $\mathrm{O}$ ritmo de trabalho é intenso, sua estruturação por projetos exige adaptação constante a metas e prazos sempre renováveis. É preciso desenvolver um importante autocontrole das ansiedades e gerir metas nem sempre exequíveis.

Tal ritmo depende de um ambiente dinâmico e de projetos de inovação que pressionam o mercado a mudanças constantes. A temporalidade é uma variável estruturante da capacidade da teia organizacional de adaptar-se e modificar-se.

Então, em empresa grande de ponta, [...] as mudanças acontecem imediatamente. A gente não perde uma semana pra fazer mudança. Tem que ser uma mudança completa, changes assim de milhôes de dólares. Que às vezes tem que sentar em três dias e tomar uma decisão. Daí a gente fica assim: bah, horrível! Impacta toda a contratação de funcionários no setor. Aí tem que deixar o coraçãozinho em casa um pouquinho, pra proteger desse lado um pouco do mal. [...] Infelizmente o coração a gente tem que deixar em casa, e vem pro trabalho porque às vezes tem que tomar uma decisão. Que na verdade parece que é ruim, mas por outro lado eu acho que acaba salvando muita gente... né? (Homem, 36 anos, 12 anos de TI, CLT).

O ethos social que os quadros superiores das grandes corporações representam pode ser caracterizado como uma forma de individualismo sem sujeito, vivendo em uma situação de independência sem autonomia (cf. Lopez-Ruiz, 2007). É preciso estar sempre atento às possibilidades de migrar e enfrentar novos desafios, sem que haja necessariamente suportes coletivos nas empresas que permitam vislumbrá-las. Ter empregabilidade, para além do acúmulo e variabilidade de experiências em diversos projetos, depende da rede de relações que se tece quando da vivência de diferentes situações de trabalho ("o que valeu para chegar a essa posição foram os meus 
contatos anteriores, eu tinha, em diversas ocasiões, trabalhado com aquelas pessoas"). As carreiras são autogeridas, os quadros superiores são donos do próprio destino.

Eu não me importo de me esforçar pra ter uma certificação, e me esforçar pra me aperfeiçoar, porque é pra mim, ninguém vai tirar isso de mim. Não que a empresa não tenha que investir no funcionário, mas acho que o funcionário tem que investir em si. Porque a empresa pode perder o funcionário, o funcionário não perde o conhecimento que ele adquiriu. Então, eu tô investindo em mim e a empresa tá usufruindo desse investimento. E ela tem que pagar por isso (Mulher, 29 anos, 8 anos de TI, CLT).

Há a institucionalização da mobilidade e da flexibilidade, de maneira que a autogestão dos percursos profissionais traz consigo a busca incessante por uma progressão infinita (a permanência no emprego e/ou na ocupação depende de uma perspectiva sempre atual de ganhos futuros e de ascensão profissional).

É, na realidade, é assim, eu encontro segurança em mim, na minha capacidade, nos meus pontos fortes. $\mathrm{O}$ que que uma empresa vai ganhar me contratando? Então, é na confiança das minhas conquistas, do que eu entrego, do que eu agrego de valor, sempre mantendo um olho, assim, na questão da especialização. Sempre não deixando de aprender coisas novas, de tá olhando oportunidades dentro da empresa mesmo, de movimentos estratégicos de carreira (Homem, 34 anos, 13 anos de TI, CLT).

Este empregado é dono do seu próprio destino e do valor que agrega à organização: se ele vence o mérito é seu, se ele fracassa a responsabilidade é sua.

Essa é a minha trajetória. Então ainda tem muita coisa, por isso que eu tô me movendo, tentando, né? Tentando me mover um pouco de área em área, e me colocar em situaçōes indigestas. Ah, porque eu gosto de desafio, eu gosto, que é onde eu aprendo. Só pra ter uma ideia, nesse projeto que no ano passado inteiro eu trabalhei, fiquei muito tempo nos Estados Unidos, fiquei praticamente uns oito meses viajando. Ficando três semanas lá, uma semana aqui, foi um negócio muito complicado. Várias pessoas, vários diretores, assim, quase todo mundo caiu, né? Assim, tu pega diretor, caíram uns dois, caíram três gerentes seniores, caíram três ou 
quatro. Caíram muitos nesse projeto, caiu muita gente. $\mathrm{O}$ único que não caiu fui eu, né? Eu não sou genial nem nada, mas eu consegui me movimentar na forma... eu tava tentando fazer a coisa certa. Mas várias pessoas chegaram: cai fora, cai fora que tu vai ser o próximo. Pessoas altamente experientes, a pessoa que me contratou pra cá, uma pessoa altamente experiente: sai, porque esse negócio tá afundando e tu vai afundar junto. E eu acreditava naquilo ali, e eu não desisti. Então, isso vem me fortalecendo. Cada barreira que eu venho ultrapassando vem me fortalecendo cada vez mais. Então essa é a minha visão (Homem, 36 anos, 12 anos de TI, CLT).

No entanto, esse fortalecimento pessoal alimentado pelo sucesso e por "não ter caído" no caminho tem custos pessoais. O comprometimento e o engajamento no trabalho exigem a gestão da subjetividade em prol do sucesso na carreira.

É, a vida pessoal fica bem comprometida. Voltei pra academia agora [...] eu tenho procurado, final de semana se tiver tempo bom eu saio, dou minha caminhada. [...] Eu tento levar uma vida saudável, assim, ter uma alimentação bem saudável, fazer exercício, não fumo... Eu sei que isso aí é um dos pilares pra eu conseguir tocar todo o resto. Mas é difícil preservar os amigos, é difícil ter amigo que queira fazer uma visita ou fazer alguma coisa contigo depois das dez da noite [risos], que é a hora que eu chego em casa, é difícil ter, preservar um relacionamento por conta desse... fica complicado. Mas tô pagando o preço! Na carreira, eu quero crer que isso vai ter um resultado. Sempre apostei muito na minha carreira! Sempre apostei! (Mulher, 36 anos, 10 anos de TI, CLT).

A gestão de si depende do reconhecimento. O que permite a consciência do próprio valor é a possibilidade de negociar a si mesmo no mercado de trabalho. O reconhecimento vem da empresa e do mercado de trabalho, espaços "institucionalizados" de luta por reconhecimento para os quadros superiores de TI. Lutar por reconhecimento significa correr riscos, o que, por sua vez, fortalece a identidade profissional fundamentada no "eu" (cf. Mossi, 2009).

Em um quadro de identidade profissional fundamentada no "eu", a falta de reconhecimento é tida como uma dor e um fracasso pessoal.

Eu tava um pouco desiludido, assim, com o mercado pelo fato de ter sofrido uma dispensa, né? Numa empresa que, teoricamente, eu tava me esforçando bastante, assim. Não acreditava que o meu trabalho não agregasse valor a ponto de ser dis- 
pensado. E aí depois eu fui pra uma outra empresa que não me pagou três meses [risos], então, eu fiquei um pouco baqueado, assim, meio desiludido. E eu tava num momento da minha carreira que eu tava tentando construir um legado, assim, pra, pra... pra ter uma história, ter uma coisa mais concisa em termos de ter uma base sólida pra progredir na carreira (Homem, 34 anos, 13 anos de TI, CLT).

É possível, de maneira sucinta, afirmar a institucionalização da instabilidade a partir das dimensóes da vivência do trabalho explicitadas por esses extratos de entrevista, a saber: 1) mobilidade no interior das empresas e entre diferentes empresas; 2) conciliação do paradoxo de gerir a mobilidade e a estabilização; 3) referência, por meio dessa gestão, ao empreendedorismo do empregado; 4) vínculo de trabalho ora como assalariado, ora como prestador de serviço exclusivo mas autônomo; 5) construção de redes de contatos para se manter no mercado de trabalho; 6) nova temporalidade marcada pelo dinamismo e renovação infinitos; 7) necessidade de correr riscos como única forma de reconhecimento; 8) identidade profissional baseada no "eu" e aparentemente livre das coerções de natureza social; e, por fim, 9) comprometimento e engajamento pessoais como fontes de segurança.

\section{Considerações finais: a justificação da precarização}

Os quadros superiores ou chefes de projetos de empresas de TI personificam essa nova fase do capitalismo devido ao seu perfil de atores móveis e empresários de si mesmos. Enquanto para os demais trabalhadores se trata de aprofundar o seu compromisso com a empresa, esse profissional de alta renda torna-se independente a partir de seu valor e suas competências pessoais. É a figura do trabalhador empreendedor de si mesmo que deve gerir autonomamente sua carreira e a própria vida segundo as regras do capital, o que remete a uma injunção paradoxal.

A mobilidade e a empregabilidade são condições da flexibilização do trabalho de TI entre os quadros superiores. É possível afirmar o "empoderamento" pessoal e uma flexibilidade qualificante associados a uma fragilização do laço social, mais do que do indivíduo tomado isoladamente. A mobilidade dos quadros superiores significaria, assim, uma nova relação com o trabalho marcada pela flexibilidade positiva e uma gestão da justificação de um contexto de fragilização e precariedade do laço social através do trabalho (entendido como meio por excelência de inserção na sociedade capitalista), segundo a noção defendida por Honneth (2008) de que o trabalho possui 
valor imanente no que se refere às formas de reconhecimento social. A fragilização do laço social pode ser identificada no enfraquecimento dos vínculos sociais quando este trabalhador de alta renda se relaciona, antes de tudo, com seu próprio percurso profissional.

É possível identificar um fortalecimento subjetivo deste trabalhador classificado como um quadro superior, uma flexibilidade qualificante, aliada a um engajamento individualizante (cf. Alves, 2008) ${ }^{6}$ que significa fragilização social (e que, no entanto, individualmente pode não ser assim identificada). Convivem lado a lado sentimento de força e mérito pessoal com a tensão de adaptabilidade infinita que remete a um engajamento individualizante: eles estão sós, para o bem e para o mal. Tudo o que remete às suas carreiras e percursos é mérito próprio ou sua própria responsabilidade a gerir e resolver. Mas há uma dinamicidade e um desejo de superação que não é somente fragilização. Trata-se de um sentimento de poder pessoal ligado à ação, à iniciativa, à volatilidade, aos desafios sempre renováveis. Um modelo de justificação do risco e do mérito pessoais, como mostra a passagem seguinte.

\section{P: Essa pressão te tira o sono?}

R: Tira, tira, tira. Principalmente porque eu não gosto de operar. Operar significa quando tu entra no ciclo repetitivo das coisas. [...] O que me preocupa é que tem que fazer a mesma coisa hoje e amanhã, fez ontem, aí me tira a inspiração. Pra mim a coisa tem que ser na diversidade. [...] É óbvio que o tirar o sono tem os dois lados também. O tirar o sono porque eu não tô conseguindo dormir bem pela responsabilidade da história; mas tem o outro lado que é pelos insights, né? [...] A pressão é importante. Mas a estória do colesterol bom e ruim é assim: tu ficar acordado, ou tu ter insights por estar pensando, desenvolvendo coisas que no dia seguinte tu quer compartilhar com algumas pessoas da tua equipe: vamos fazer isso. Não cheguei ao ponto de ligar pros caras de madrugada. [...]

P: Tu ficarias num emprego estável bem pago?

R: Jamais. Jamais. Jamais, porque eu morreria de tédio, entendeu? Então o outro lado, que é o da preocupação de "tenho que fechar o mês com tal coisa". Então, esse é obviamente o fardo da responsabilidade. E aí tem um lado, de tu dizer assim, “oh, eu vou ficar só a parte boa e vou deixar a ruim”. Tu leva as duas, né? E nesse ponto, mesmo quando tu muda de job dentro da própria empresa, sempre as duas vêm juntas (Homem, 50 anos, 14 anos em TI, PJ).
6. "Engajamento individualizante na flexibilidade indica que subjetivamente o indivíduo estaria aderindo, por um lado, aos discursos $\mathrm{e}$ às práticas que o consideram como a fonte da produtividade de seu trabalho, responsável pela gestão de seu próprio trabalho, formação profissional e carreira, e, por outro, aos discursos e práticas de flexibilidade do trabalho, no sentido espaço-temporal e no sentido da organização do trabalho e do emprego. Significa também que o indivíduo seria considerado autor de seu próprio trabalho e responsável direto pelos resultados de sua atividade. Nesse sentido, o controle e a organização do trabalho não ocorreriam sem o engajamento e o comprometimento do indivíduo no trabalho" (Alves, 2008, p.8). 
Há uma obrigação de ascensão infinita e competências sempre renováveis como condição de permanência. Mas não há qualquer segurança efetiva de que ela se realize: socialmente não há garantias, e o mérito pessoal e seu reconhecimento passam a ser as únicas fontes, a priori, confiáveis. É bem verdade que estamos diante de um mercado de trabalho aquecido, dinâmico e longe de sua saturação, mas estes experts de hoje podem não mais ser os de amanhã.

$\mathrm{Na}$ ausência de qualquer garantia, este trabalhador de alta qualificação crê em seu talento, competência, e em seu "perfil" para enfrentar a imprevisibilidade real do futuro. Entre essas qualificações está a sua capacidade de criar espaço de diferenciação em relação aos demais (cf. Luci, 2007). Nas organizações por projetos e de gestão por objetivos, a valorização de si requer não só atingir os objetivos fixados, mas, de preferência, superá-los, sobressaindo-se e distinguindo-se em relação aos outros. $\mathrm{O}$ sucesso depende de se arriscar, se superar e se mostrar, a fim de fazer reconhecer sua singularidade. A gestão permanente do "eu" faz da subjetividade elemento a ser administrado com o intuito de configurar estratégias bem-sucedidas. A recorrência, nas entrevistas, da exposição do "perfil" pessoal, e aparentemente imanente, remete à gestão da subjetividade em prol da construção de um papel de vencedor, de diferenciação e superação em relação aos demais, como se pode ver no extrato de entrevista seguinte.

P: Talvez tenha alguma coisa que tu aches importante, algo que não mencionamos que tu gostarias de dizer?

R: Eu acho que só... só reforçando, que eu olho muito pra minha trajetória, na verdade, desde o meu primeiro emprego lá como office boy eu já tinha algumas, já realizava algumas ações, algumas atividades de coordenação, de liderança. Eu acho que isso já vem... talvez por isso explique o meu papel hoje, isso já vem desde cedo. É só essa... (Homem, 33 anos, 10 anos de TI, CLT).

Enquanto Honneth (2008) demonstra que, embora nem todo trabalho possa ser obra, todos eles pressupōem um valor imanente de contribuição ao global, o trabalho por projeto permite e favorece a reabilitação da noção de trabalho como obra, como local de criação, uma vez que se fundamenta na performance individual (cf. Luci, 2007). No entanto, o sucesso só é possível através da construção de redes de contatos e de cooperação. O sucesso e a gestão do percurso são individuais, mas se realizam unicamente através relaçôes com os pares. 
Se o empreendedorismo do trabalhador traz para si a responsabilidade e a gestão de carreira, o ator constrói o discurso da independência e da autonomia (e, portanto, é indiferente dispor de um contrato sob a égide da CLT ou se constituir como uma pequena empresa e responder como Pessoa Jurídica). As regras a que está submetido se tornam opacas e aparentemente ausentes, dada a independência de que dispóe. Os constrangimentos sociais passam à gestão individual e perdem aparentemente seu caráter coercitivo.

A teoria crítica de Axel Honneth (2006) parece ter uma notável contribuição a dar no processo de entendimento do paradoxo, presente nessa fase do capitalismo, entre uma concepção normativa da emancipação e os potenciais de destruição e negatividade desses elementos de emancipação. No que se refere especificamente ao nosso objeto, a emancipação repousaria sobre autonomia, mobilidade e liberdade de escolhas, ao mesmo tempo que a outra face da emancipação remeteria à precarização e à fragilização decorrentes de sua instrumentalização.

A tese sustentada por Honneth é de que essas aquisições institucionalizadas (normas e valores) - ganhos morais legados da era social-democrata do pós-guerra - são instrumentalizadas pelo capitalismo flexível, no sentido de que este tem sucesso em "guardá-las" ao mesmo tempo em que logra erodir seu caráter emancipador. No entanto, essa contradição não é percebida como atrelada ao capitalismo, pois os sujeitos "tornaram-se" responsáveis de seus destinos e empresários de si mesmos, aparentemente permanecendo autônomos em relação às imposições do sistema. Esse é o paradoxo central do capitalismo contemporâneo.

As regras do sucesso são explicitadas a partir das capacidades e competências dos atores, e para tornar-se vencedor é preciso aderir às suas premissas, tornando opacas as justificativas morais que as sustentam. Ao aderir aos termos que conduzem ao sucesso, cria-se um mecanismo de justificação aqui entendida em seu sentido ético, ou seja, ela é um raciocínio moral que demonstra a aceitabilidade e a plausibilidade da norma (cf. Ferrater Mora, 2001) -, no qual desaparecem as formas de dominação, assim como os constrangimentos e as coerçôes de natureza social. Ora, se os atores são senhores de seu destino e não possuem garantias sociais, não estaríamos diante de uma justificação da precarização?

Precarização é aqui interpretada como uma condição mais ampla de instabilidade e insegurança no trabalho. Trata-se de precarização social, no sentido dado por Appay e Thébaud-Mony (1997), uma "dupla institucionalização da instabilidade", econômica e social, o que significa que ultrapassa a reali- 
dade do desemprego ou das formas inseguras de inserção e torna o trabalho e o emprego espaços marcados por instabilidade, incerteza, insegurança, imprevisibilidade, adaptabilidade e risco. Se a identificação da precariedade dá-se usualmente pela noção de pauperização, as autoras propõem o uso do conceito com base na análise do próprio trabalho, suas relações, condiçóes e vivência. Assim, não se trata simplesmente de formas de instabilidade, mas de uma institucionalização e legitimação da instabilidade: "O termo de precarização é utilizado, [...] [e] não o de precariedade, para evidenciar os processos referentes a ser colocado em precariedade, e não um estado ou estados que dizem respeito às populaçõos vulneráveis" (Idem, p. 512).

Se comumente a noção de trabalho precário se reporta ao trabalho socialmente empobrecido, desqualificado, informal, temporário e inseguro, a noção de precarização aqui adotada remete a um processo social de institucionalização da instabilidade. Se os trabalhadores de altos salários e inseridos em boas condiçôes vivem o trabalho como aventura pessoal, sua inserção social denota distanciamento que beira o isolamento. Isso assume contornos de uma autogestão de percursos, livre e voluntária, inerente ao indivíduo, de maneira que se estabelece um cenário em que os indivíduos estão além de qualquer enquadramento ou constrangimento social. $\mathrm{O}$ empreendedorismo de si mesmo assume contornos morais de justificação de uma instabilidade aparentemente escolhida. Não se trata de um trabalho precário, visto estarmos diante de um trabalho decente. De acordo com a Agenda do Trabalho Decente criada em 1999 pela OIT: "O Trabalho Decente é um trabalho produtivo e adequadamente remunerado, exercido em condiçôes de liberdade, equidade e segurança, sem quaisquer formas de discriminação, e capaz de garantir uma vida digna a todas as pessoas que vivem de seu trabalho [...]" (apud Druck, 2009, p. 6).

Ora, se o trabalho dos quadros superiores de TI pode ser considerado decente, é evidente que não se trata de um trabalho precário. Não obstante, o conceito de precarização social (cf. Appay, 2005) logra superar a separação entre o aumento da flexibilidade produtiva e a análise de suas consequências sociais. Em outras palavras, segundo a autora, o conceito coloca em perspectiva um duplo processo: o de precarização econômica que resulta da flexibilização salarial e das reestruturaçóes produtivas, e o da institucionalização da precariedade, procedente das transformações legislativas referentes ao trabalho e à proteção social. Argumentamos que o conceito de precarização social permite, ainda, definir a institucionalização da instabilidade e configurar a sua justificação como se fosse um valor moral 
aceitável, a ser dirigido individualmente por cada ator na autogestão das carreiras e de sua inserção social ${ }^{7}$.

Pesquisa europeia sobre a "evolução da formação continuada ante as mudanças das situações profissionais dos cadres das empresas da net-economia na Europa do Sul", no âmbito do projeto europeu Forcoprecanet, realizada entre 2002 e 2005 (apud Saint-Martin, 2007), especificamente no que tange a seus resultados para a França, evidenciou o sentimento de fragilização experimentado pelos cadres em função, de um lado, dos resultados auferidos pelas empresas e suas consequências sobre os benefícios disponibilizados para proprietários, acionistas ou trabalhadores, e, de outro, da questão geracional, atrelada ao momento do ciclo de vida e de trajetória ocupacional. Os que se sentem fragilizados possuem, em sua maioria, 41 anos de idade, são casados e têm filhos pequenos. Os que não se sentem dessa forma estão na faixa de 21 a 30 anos, solteiros, sem filhos. Esses dados corroboram a nossa hipótese de que a noção de risco e instabilidade como uma aventura rumo ao sucesso pode não se sustentar no tempo, e o paradoxo entre se superar constantemente e também se estabilizar se impõe como uma injunção impossível de ser ultrapassada. Assim, se para os mais jovens este mercado de trabalho é suficientemente atrativo em função de suas possibilidades, autonomia e aventura, para os mais velhos é preciso conjugar a aventura com a segurança. Ambos os engajamentos necessitam da adesão às normas, aos valores morais, às referências, mas também às condições de trabalho próprias ao setor:

A apreensão dos constrangimentos repousa sobre a externalização dos fatores (econômicos, tecnológicos, políticos) e a condição inerente à integração profissional nesse setor de atividade é de saber aceitar o risco. Estamos diante de um processo que marca finalmente uma certa normalização da precariedade profissional. E essas condições externas, sobre as quais o indivíduo considera não ter ingerência, constituem, aparentemente, uma maneira de aceitar, justificando-as, as condiçôes de trabalho dadas, de construir sistemas de referência para o trabalho que privilegiam o risco ou a ameaça como elemento intrínseco à atividade profissional, e simultaneamente idealizando: "uma paixão", "um desafio", "uma aventura”. É a regra do jogo que não se pode ignorar, um elemento forte que confere sentido ao trabalho $\mathrm{e}$ assim a formas insidiosas de precariedade profissional (Saint-Martin, 2007, p. 10).

A precarização social significa, pois, um direcionamento da responsabilidade social para uma crescente individualização. Esta, por sua vez, implica a interiorização do princípio de responsabilidade individual (cf. Le Lay, 2007),
7. Poder-se-ia perguntar se não é característica do capitalismo a instabilidade, tendo sido a estabilidade salarial um momento específico no quadro da precarização que sempre definiu o trabalho na sociedade capitalista. Logo, a precarização não seria um fenômeno novo mas somente um retorno à tradicional exploração do trabalho após um período excepcional de pleno emprego na sociedade salarial, especialmente na França. Nosso argumento é de que a novidade repousa na instabilidade como valor moral partilhado no conjunto da sociedade e sua consequente naturalização. 
de maneira que $\mathrm{o}$ ator adere às normas comportamentais e valores esperados para que se torne senhor do seu destino. Ora, a fragilização dos laços sociais decorrente da individualização preconizada como autonomia constitui-se como um processo de precarização. $\mathrm{Na}$ medida em que os indivíduos se responsabilizam pelas suas diferentes formas de inserção social e tomam isso como um ato voluntário, é preciso aderir a um sistema de justificação que permita a ele se perceber como livre e autônomo. As noções de empregabilidade, autogestão de carreira, empreendedorismo de si próprio impedem que se perceba o trabalho como uma forma de contribuição ao todo social, pois o mérito retorna ao sujeito sob forma de sucesso do "eu" e de mérito pessoal -e, portanto, leva à percepção de que o trabalho é simplesmente uma contribuição pessoal à empresa e/ou organização. A própria noção de carreira transforma-se e mesmo coloca em xeque o conceito, uma vez que não há eixo a ser percorrido (a não ser o da ascensão), mas, sim, um sujeito no trabalho que se adapta e se molda a um mercado em constante mutação, que é levado a contar apenas consigo mesmo e a se posicionar como senhor do seu destino. O individualismo é a um só tempo autonomia e fragilização social.

\section{Referências Bibliográficas}

Alves, Daniela. (2008), Gestão, produção e experiência do tempo no teletrabalho. Porto Alegre, tese de doutorado, Programa de Pós-Graduação de Sociologia da UFRGS. Appay, Béatrice. (2005), La dictature du succès. Paris, L'Harmattan.

\& Thébaud-mony, Annie. (1997), Précarisation sociale, travail et santé. Paris, Iresco.

Boltanski, Luc. (1982), Les Cadres: la formation d'un groupe social. Paris, Minuit. \& Chiapello, Eve. (1999), Le nouvel esprit du capitalisme. Paris, Gallimard. \& ThÉVEnOT, Laurent. (1991), De la justification. Paris, Gallimard.

Bouffartigue, Paul. (2001), "La fonction d'encadrement: de l'importance du travail dans l'étude cadres. http://hal.archivesouvertes.fr/docs/00/05/28/98/PDF/ docw2001fonctencadrement.pdf, consultado em 4/9/2009.

\& Pochic, Sophie. (2001), “'Cadres nomades': mythe et réalités. À propos des recompositions des marchés du travail des cadres". Disponível em <http://halshs. archives-ouvertes.fr/halshs-00007517>, consultado em 4/4/2008.

Castells, Manuel. (1999), A sociedade em rede. São Paulo, Paz e Terra.

Druck, Graça. (2009), "Principais indicadores da precarização social do trabalho no Brasil”. XIV Congresso Brasileiro de Sociologia, Rio de Janeiro. Disponível em <http://www.sbs2009.sbsociologia.com.br>, consultado em 16/10/2009. 
FAlCOZ, Cristophe. (2001), "La carrière 'classique' existe encore". Disponível em <http://annales.com/gc/2001/gc06-2001/falcoz04-17.pdf>, consultado em 17/2/2008.

Ferrater mora, José. (2001), Dicionário de filosofia. São Paulo, Loyola.

Honneth, Axel. (2006), La société du mépris; vers une nouvelle théorie critique. Paris, La Découverte.

. (2008), "Trabalho e reconhecimento: tentativa de uma redefinição". Civitas - Revista de Ciências Sociais, Porto Alegre, 8 (1): 46-67, jan.-abr.

LE LAY, Stéphane. (2007), Contribution à une approche archéologique de la précarisation sociale. Journées Internationales de Sociologie du Travail (JIST), Londres, CD-ROM.

Lopez-Ruiz, Osvaldo. (2007), Executivos das transnacionais e o espirito; capital humano e empreendedorismo como valores. Rio de Janeiro, Azougue.

LuCI, Florencia. (2007), Ce que réussir veut dire. Jeunes managers et gestion de soi: les enjeux du succès dans des grandes entreprises en Argentine. Journées Internationales de Sociologie du Travail (JIST), Londres, CD-ROM.

Monchatre, Sylvie. (2007), "Des carrières aux parcours: en passant par la competence”. Sociologie du Travail, Paris, 49 (4): 514-530.

Mossı, Thays. (2009), "A estabilidade do "eu” na instabilidade da relação com o trabalho: identidade profissional dos quadros superiores de TI". Porto Alegre, Relatório de Pesquisa (Iniciação Científica). Instituto de Filosofia e Ciências Humanas da UFRGS.

Rosenfield, Cinara \& Nardi, Henrique. (2006), "Competência”. In: Cattani, Antonio David \& Holzmann, Lorena (orgs.). Dicionário de trabalho e tecnologia. Porto Alegre, Editora da UFRGS, vol. 1, pp. 62-65.

SAINT-MARTIN, Corinne. (2007), La précarisation professionnelle des personnels qualifiés des entreprises de la net-économie. Journées Internationales de Sociologie du Travail (JIST), Londres, CD-ROM.

SANTOS, Laymert Garcia dos. (2007), "Apresentação". In: Lopez-Ruiz, Osvaldo. Executivos das transnacionais e o espirito; capital humano e empreendedorismo como valores. Rio de Janeiro, Azougue. 


\section{Resumo}

\section{Trabalho decente e precarização}

$\mathrm{Na}$ atual fase do capitalismo, as empresas de ponta são organizadas por projetos. Para os trabalhadores a valorização recai sobre a capacidade de adaptação e de gestão de suas empregabilidades através do engajamento em projetos transitórios. Nosso objetivo é refletir se essa adaptabilidade significaria uma nova relação com o trabalho marcada pela flexibilidade positiva ou seria uma justificação de um contexto de precarização. Com base na análise das vivências dos quadros superiores de empresas de TI, atores emblemáticos de trabalho considerado decente, desenvolvemos a hipótese de um "empreendedorismo de si mesmo" que se configura como justificação da precarização, aqui entendida como processo de institucionalização da instabilidade.

Palavras-chave: Quadros superiores; Trabalho informacional; Precarização social; Sistema de justificação moral.

\section{Abstract}

Decent work and precariousness instability

In the current phase of capitalism, leading companies are primarily organized through projects. Workers are valued according to their ability to adapt and manage their employability through their commitment to transitory projects. The present study explores the question of whether this adaptability signals a new relationship to work involving a positive flexibility, or simply a management regime used to justify heightened job vulnerability. Through an analysis of the experiences of employees working in the upper levels of IT firms, the text develops the hypothesis of 'self entrepreneurship', which emerges as a justification for social vulnerability, understood here as a process of institutionalizing instability.

Keywords: IT Work; Job vulnerability; Upper levels of IT firms; Regime of moral justification. 